\title{
Empowerment Beliefs and Intention to Uptake Cervical Cancer Screening: Three Psychosocial Mediating Mechanisms
}

\author{
ALEKSANDRA LUSZCZYNSKA, PhD \\ Trauma, Health, E Hazards Center, University of Colorado, Colorado Springs, Colorado, \\ USA, and Warsaw School of Social Sciences and Humanities, Warsaw, Poland
}

ALICJA B. DURAWA, MA

Warsaw School of Social Sciences and Humanities, Warsaw, Poland

URTE SCHOLZ, PhD

University of Bern, Bern, Switzerland

NINA KNOLL, PhD

Freie Universität Berlin, Berlin, Germany,

and Charité-Universitätsmedizin Berlin, Berlin, Germany

\begin{abstract}
Three studies tested if the associations between women's empowerment beliefs and intentions to attend cervical cancer screening could be explained by mediating psychological mechanisms: control-related beliefs, well being-related beliefs, and beliefs and evaluations referring to social functioning. Data were collected from January to March 2011 in the rural and urban areas across regions of Poland. Study $1(N=386)$ indicated that women with strong empowerment harbored stronger self-efficacy and beliefs that screening participation would make them feel in control of their own health and body. These two types of cognitions were, in turn, associated with stronger cervical cancer screening intentions. Results of Study $2(N=527)$ confirmed three significant well
\end{abstract}

Aleksandra Luszczynska was supported by a Siemens healthcare sector grant (Siemens Report: 1000 women, 1000 barriers) and a Foundation of Polish Science grant (Health Behaviors and Life Cycle). The contribution by Alicja B. Durawa was supported by the Foundation of Polish Science.

Address correspondence to Aleksandra Luszczynska, PhD, Trauma, Health, \& Hazards Center, University of Colorado at Colorado Springs, 1420 Austin Bluffs Pkwy., Colorado Springs, CO 80933-7150. E-mail: aluszczy@uccs.edu 
being-related mediators in the relationship between empowerment beliefs and cervical cancer screening: perceived benefits of screening related to well being, appearance satisfaction, discomfort-and shame-related barriers for screening. Finally, Study $3(N=424)$ showed that empowerment enabled receiving higher social support for cervical cancer screening, promoted perceiving fewer barriers for cervical cancer screening-related communication and more social benefits of engaging in cervical cancer screening. Support for cervical cancer screening, social barriers, and benefits were, in turn, related to screening intentions. Across the studies similar shares of intention variance were explained, and thus the bypothesized mediating mechanisms may have similar explanatory power.

KEYWORDS cervical cancer, screening, empowerment, intention, mediation

\section{INTRODUCTION}

Empowerment may be defined as a system of beliefs, referring to the ability to make decisions, access information, and use social and internal resources (McAllister et al., 2008), or as a system of beliefs enabling people to attain their goals in an independent manner (Johnson, Worell, \& Chandler, 2005). Contrary to other approaches which accentuate the role of internal regulation in decision making (Bandura, 1997; Schwarzer, 2008), the theory and the construct of empowerment emphasizes the role of environment, its perception, and its regulation (cf. Johnson et al., 2005; Worell, 1996). Although women's empowerment may be seen as the outcome of womencentered interventions, it is also conceptualized as a determinant of women's decisions and actions in the context of health care (Wittmann-Price, 2006). Besides the discussion on empowerment representing a correlate, process, or the outcome, scientists debate whether empowerment can be conceptualized as a more general variable (Johnson et al., 2005) or always be analyzed as a context-specific characteristic (McAllister et al., 2008). In this article empowerment was defined as a generalized set of beliefs referring to perceptions of the self and the environment, in particular beliefs and perceptions of power and competence, resource access, assertiveness, autonomy, personal strength, and social activism (Johnson et al., 2005).

\section{How Does Empowerment Operate?}

Although the concept of empowerment has drawn much attention in studies of health-care utilization, much less is known about the psychological 
mechanisms through which this construct may operate. Johnson et al. (2005) hypothesized that empowerment enables women to access and use internal and external resources successfully, and leads to higher resilience in face of obstacles. In a model of women's decision making about the use of health care, Wittmann-Price (2006) suggested that women's decisions depend on empowerment, knowledge, internal and environmental characteristics, and the perceptions of the environmental barriers and opportunities. Both approaches pointed to the role of the perceptions of the internal and environmental resources, as well as barriers and opportunities, which may form the mechanisms mediating between empowerment and decision to use healthcare.

The mechanisms suggested in empowerment theories (Johnson et al., 2005; Witmann-Price, 2006) are in part similar to mechanisms assumed in health behavior theories. Social Cognitive Theory (Bandura, 1997), and the Health Action Process Approach (Schwarzer, 2008) share the assumption that perceived barriers or perceived opportunities (or expected positive or negative consequences of behavior) are crucial determinants of intentions. Self-efficacy beliefs, referring to perceived ability to pursue one's goals in spite of barriers, are also recognized as powerful determinants of intentions (Bandura, 1997). Social support is another concept which operates in concert with efficacy beliefs (Luszczynska, Sarkar, \& Knoll, 2007).

Empowerment beliefs may be considered similar to such control-related beliefs as self-efficacy, but several conceptual differences exist between these types of beliefs. Empowerment beliefs refer to any goals or efforts to achieve better well being (McAllister et al., 2008) and they are expected to affect a wider range of cognitions and behaviors (cf. Johnson et al., 2005). Empowerment beliefs refer to specific environmental obstacles which prevent women from attaining their own goals (Johnson et al., 2005). In contrast, self-efficacy refers to specific behavior-related goals and a wide class of any internal or external obstacles which may prevent the individual from achieving these goals (Bandura, 1997). While self-efficacy is directly related to behaviors and goals (Schwarzer, 2008), empowerment beliefs are assumed to operate indirectly, as they enable women to access individual or environmental resources (Johnson et al., 2005).

In line with the mentioned health-behavior theories and operational definitions of empowerment proposed by Wittmann-Price (2006) and Johnson et al. (2005) the authors assumed that empowerment beliefs would relate to intentions, and that this relationship would be mediated by perceived barriers and pros, self-efficacy beliefs, and social support. Further, the empowerment construct relates to several areas of social and psychological functioning, such as emotional well being, sense of control, ability to use social/environmental resources and overcome social/environmental barriers, and social well being (cf. Beteta, 2006; Johnson et al., 2005; McAllister et al., 2008). Therefore, the authors assumed that empowerment might operate 
through mechanisms referring to: (1) control-related beliefs, (2) beliefs and evaluations referring to social functioning, and (3) evaluations and beliefs about emotional functioning and well being.

\section{Cervical Cancer Screening and Related Cognitions}

Cervical cancer screening (CCS) targets the reduction of cancer incidence and reduces mortality rates (cf. Arbyn et al., 2009). Across Central and Eastern European countries cervical cancer is a considerable public health problem, with higher incidence and mortality rates than in Western Europe (Arbyn et al., 2009). These differences in cervical cancer mortality trends can be most plausibly_and at least partially-explained by the differences in screening participation (Arbyn et al., 2009). The present research targeted CCS in Poland, where the first population-based, nation-wide screening program was initiated in 2007 (Spaczynski et al., 2010). CCS in Poland is publicly funded and free of charge, but between 2007 and 2009 only 28\% of women participated in population-based screening (Spaczynski et al., 2010). A similar percentage of women attended opportunistic screening in clinics outside of the population-based program, adding up to $56 \%-67 \%$ of population undertaking CCS (Spaczynski et al., 2010; Ulman-Wlodarz et al., 2011). The CCS procedures are similar to those offered in other population-based screening programs in Europe (Spaczynski et al., 2010). The recommended screening interval is 1-3 years (depending on women's age), with the first screening recommended to take place not later than age 21 years (Spaczynski et al., 2010).

Social and cognitive variables are strongly related to CCS intentions. Beliefs about one's ability to participate in CCS, regardless of barriers relate to screening behavior (Knops-Dullens, de Vries, \& de Vries, 2007) and intentions to take up recommended CCS (Breitkopf \& Pearson, 2009). A broad range of perceived barriers is related to CCS (Tanner-Smith \& Brown, 2010). Those significant barriers include expectations of discomfort and shame related to CCS participation (Eaker, Adami, \& Sparen, 2001; Luszczynska et al., 2011; Knops-Dullens et al., 2007) and barriers in communication with medical professionals, family, and friends (Eggleston et al., 2007; KnopsDullens et al., 2007). CCS pros may refer to expectations about control (over ones' body and health), well being (feeling happy), and positive effects for social relationships (doing something good for a life partner) (Luszczynska et al., 2011).

Besides constructs embedded in health behavior theories, perceptions of one's body and its appearance may be a relevant mediator in the relationship between empowerment and CCS intentions. Empowerment models suggest that aspects of body acceptance, control, and satisfaction are important but not sufficiently accounted for in women empowerment studies (Betata, 
2006). Satisfaction with body and physical appearance relates to screening intentions (Chait, Thompson, \& Jacobsen, 2009).

\section{PURPOSE}

Three consecutive studies were conducted, aimed at testing associations between women's empowerment beliefs and intentions to attend CCS and if they could be explained by three mediating psychological mechanisms: control-related beliefs, well being-related beliefs and evaluations, and beliefs and evaluations referring to social functioning. In particular, the authors hypothesized that: (1) self-efficacy and control-related pros would mediate between empowerment beliefs and CCS intentions (Study 1); (2) discomfort and shame-related barriers, well being-related pros, and appearance satisfaction would mediate between empowerment beliefs and CCS intentions (Study 2); and (3) social support for screening, communication-related barriers and pros referring to social functioning would mediate between empowerment beliefs and CCS intentions (Study 3). The authors hypothesized that empowerment would lead to stronger self-efficacy beliefs, higher satisfaction with appearance, higher perception of pros, and lower perception of barriers, which in turn would lead to higher intention to engage in CCS. Three studies were designed. Study 1 was a preliminary evaluation of assumed relationships between empowerment and CCS participation. It was followed by two studies testing the hypothesized mediating role of well being-related beliefs (Study 2) and social functioning beliefs (Study 3), applying different data collection procedures (individual-based and web-based) and thus accessing diverse groups of respondents. The protocols of the three studies were approved by the Institutional Review Board.

Knowledge about screening is a strong determinant of screening behavior (Eggleston et al., 2007; Tracy, Lydecker, \& Ireland, 2010), whereas past behavior is usually assumed to influence intentions (Ajzen, 1991). Economic status and education may be relevant correlates of empowerment beliefs (Ahmed et al., 2010). Therefore, knowledge, past behavior, economic status, and education were controlled in hypothetical models tested in the three studies. Further, the moderating role of education and age on the relationship between empowerment and the mediators were examined.

\section{STUDY 1: RELATIONSHIPS BETWEEN EMPOWERMENT AND CCS INTENTIONS MEDIATED BY CONTROL BELIEFS}

In this study the authors investigated the associations between women's empowerment and health behavior and if they would be mediated by control- 
related beliefs, such as cancer screening self-efficacy (beliefs about ability to take up CSS; cf. Bandura, 1997) and control-related pros (beliefs and expectations that CCS participation would result in positive outcomes, such as a sense of control over one's own body and health; cf. Luszczynska et al., 2011).

\section{Methods}

Data were collected for one month (January 2011) in the south and western regions of Poland. The study was advertised at the university website and at the university research center as dealing with women's health issues and providing an opportunity for counselling free of charge. Those who were interested contacted the investigators at the research center and were informed about the study aims, anonymity, and that the study did not have any commercial purposes. Women who agreed to take part signed a written informed consent. Participants were offered a free counselling session with a licensed psychologist, if they wished to discuss any issues addressed in the study. Participants were also asked to identify any other potential respondents who would be interested in the study and asked to inform them about the research. Exclusion criteria were: age below 18 or above 65 years, and past or current treatment including hysterectomy or cervix amputation. A total of $4 \%$ were excluded from analysis based on these criteria, and $2 \%$ of those eligible refused to participate.

Measures of empowerment, cervical cancer intention, past CCS behavior, self-efficacy, and knowledge were psychometrically evaluated in previous studies and showed satisfactory validity and reliability in original research, and adequate reliability of these measures was confirmed in the present study (Table 1). To assess control-related pros, three items referring to control applied in the earlier CCS study (Luszczynska et al., 2011) were used. To evaluate control variables items applied in previous research were used (Table 1).

Data analysis was conducted with SPSS 19 (SPSS Inc., Chicago, IL) and included obtaining descriptive statistics (means and standard deviations), Cronbach alpha, Cohen's kappa coefficients (reliability), and Pearson correlation coefficients. Further, path analysis with the Maximum Likelihood procedure (Byrne, 2009) was conducted using AMOS 19 (SPSS Inc., Chicago, IL). Path analysis was applied to test if empowerment was indirectly related to CCS intentions (with self-efficacy and control-related pros as the mediators). The hypothesized model included eight observed variables, representing respective mean-item scores. Sociodemographic variables (education level and perceived economic status) were specified as the variables associated with empowerment. Additionally, education was assumed to relate to knowledge about CCS, which in turn was assumed to relate to past screening behavior. Empowerment was expected to be related to the mediators, that is control- 
TABLE 1 Measures and Descriptive Statistics in Studies 1-3

\begin{tabular}{|c|c|c|c|c|c|c|c|c|c|}
\hline \multirow[b]{2}{*}{ Variable } & \multirow[b]{2}{*}{ Measure and item example } & \multirow[b]{2}{*}{ Items } & \multirow{2}{*}{$\begin{array}{l}\text { Response } \\
\text { scale }\end{array}$} & \multicolumn{2}{|c|}{ Study 1} & \multicolumn{2}{|c|}{ Study 2} & \multicolumn{2}{|c|}{ Study 3} \\
\hline & & & & $M^{\mathrm{a}}(S D)$ & $\alpha$ & $M^{\mathrm{a}}(S D)$ & $\alpha$ & $M^{\mathrm{a}}(S D)$ & $\alpha$ \\
\hline $\begin{array}{l}\text { Past cervical cancer } \\
\text { screening }\end{array}$ & $\begin{array}{l}\text { "Within last three years I regularly have taken } \\
\text { part in cervical cancer screening" (CCS } \\
\text { measure, see Luszczynska et al., 2011) }\end{array}$ & 3 & $\begin{array}{l}1 \text { (not at all })-5 \\
\quad(\text { definitely yes })\end{array}$ & $3.11(0.90)$ & .74 & $3.25(0.83)$ & .71 & $3.49(.70)$ & .84 \\
\hline $\begin{array}{l}\text { Intention to uptake } \\
\text { CCS }\end{array}$ & $\begin{array}{l}\text { "I intend to attend cervical cancer screening } \\
\text { during next year" (CCS intention measure, } \\
\text { see Luszczynska et al., 2011) }\end{array}$ & 3 & $\begin{array}{l}1 \text { (not at all })-5 \\
\quad(\text { definitely yes })\end{array}$ & $3.11(0.86)$ & .75 & $3.77(0.44)$ & .82 & $3.72(0.43)$ & .70 \\
\hline Empowerment & $\begin{array}{l}\text { PPS-R scales: Perceptions of Power and } \\
\text { Competence, self-Nurturance and Resource } \\
\text { Access, Interpersonal Assertiveness, } \\
\text { Autonomy, Personal Strength and Social } \\
\text { Activism (Johnson et al., 2005) }\end{array}$ & 22 & $\begin{array}{c}1 \text { (almost never)-7 } \\
\quad \text { (almost always) }\end{array}$ & $4.73(0.61)$ & .74 & $4.74(0.64)$ & .73 & $4.89(0.67)$ & .75 \\
\hline $\begin{array}{l}\text { Knowledge of CCS } \\
\text { guidelines }\end{array}$ & $\begin{array}{l}\text { "Women should begin screening for cervical } \\
\text { cancer when they become sexually active" } \\
\text { (knowledge measure by Tracy et al., 2010) }\end{array}$ & 4 & $0-1$ & $3.64(0.60)$ & $.79^{\mathrm{b}}$ & $3.70(0.66)$ & $.69^{\mathrm{b}}$ & $3.80(0.69)$ & $.67^{\mathrm{b}}$ \\
\hline $\begin{array}{l}\text { Perceived economic } \\
\text { status }\end{array}$ & $\begin{array}{l}\text { "What is your family income compared to other } \\
\text { families" (item from: Paskett et al., 2010) }\end{array}$ & 1 & $\begin{array}{l}1 \text { (far below } \\
\text { average)-5 (far } \\
\text { above average) }\end{array}$ & $3.34(0.87)$ & - & $3.39(0.80)$ & - & $3.51(0.84)$ & - \\
\hline Education & $\begin{array}{l}\text { "What is your education: primary, high school, } \\
\text { some tertiary education, BA, MA/PhD?" }\end{array}$ & 1 & $1-5$ & $3.17(1.54)$ & - & $3.12(1.54)$ & - & $4.08(1.21)$ & - \\
\hline $\begin{array}{l}\text { Cancer screening } \\
\text { self-efficacy }\end{array}$ & $\begin{array}{l}\text { "I am confident that I am able to participate in } \\
\text { the screening even if it costs me much time" } \\
\text { (CCS self-efficacy measure by Lechner, de } \\
\text { Vries, \& Offermans, 1997) }\end{array}$ & 4 & $1-4^{\mathrm{c}}$ & $2.63(0.91)$ & .76 & - & - & & \\
\hline
\end{tabular}




\begin{tabular}{|c|c|c|c|c|c|c|c|c|c|}
\hline \multirow[b]{2}{*}{ Variable } & \multirow[b]{2}{*}{ Measure and item example } & \multirow[b]{2}{*}{ Items } & \multirow{2}{*}{$\begin{array}{l}\text { Response } \\
\text { scale }\end{array}$} & \multicolumn{2}{|l|}{ Study 1} & \multicolumn{2}{|c|}{ Study 2} & \multicolumn{2}{|l|}{ Study 3} \\
\hline & & & & $M^{\mathrm{a}}(S D)$ & $\alpha$ & $M^{\mathrm{a}}(S D)$ & $\alpha$ & $M^{\mathrm{a}}(S D)$ & $\alpha$ \\
\hline $\begin{array}{l}\text { Health control-related } \\
\text { pros }\end{array}$ & $\begin{array}{l}\text { "I would be glad that I take control over my } \\
\text { health" (health-related items from CCS pros } \\
\text { measure; see Luszczynska et al., 2011) }\end{array}$ & 3 & $1-4^{\mathrm{c}}$ & $3.25(0.55)$ & .75 & - & - & & \\
\hline $\begin{array}{l}\text { Well being-related } \\
\text { pros }\end{array}$ & $\begin{array}{l}\text { "It would increase my sense of well being" } \\
\text { (well-being related items from CCS pros } \\
\text { Luszczynska et al., 2011) }\end{array}$ & 3 & $1-4^{\mathrm{c}}$ & & & $3.51(0.57)$ & .80 & & \\
\hline $\begin{array}{l}\text { Discomfort-related } \\
\text { barriers }\end{array}$ & $\begin{array}{l}\text { "Examination is unpleasant/embarrassing" } \\
\text { (Emotional barriers scale; Eaker et al., 2001) }\end{array}$ & 7 & $1-4^{\mathrm{c}}$ & & & $2.03(0.44)$ & .85 & & \\
\hline $\begin{array}{l}\text { Appearance and } \\
\text { weight satisfaction }\end{array}$ & $\begin{array}{l}\text { "I like my looks just the way they are" (3 Items } \\
\text { from Multidimensional Body-Self Relations } \\
\text { Questionnaire; Cash, 2000) (numbers of } \\
\text { original items: } 11,30,67 \text { ) }\end{array}$ & 3 & $1-4^{\mathrm{c}}$ & & & $2.76(0.80)$ & .71 & & \\
\hline Social Support for CCS & $\begin{array}{l}\text { 3-item support scale by Eaker et al. (2001) + } 2 \\
\text { items referring to CCS ("I have someone ... } \\
\text { (a) to consult about my CCS; (b) to share my } \\
\text { concerns about CCS") }\end{array}$ & 5 & $1-4^{\mathrm{c}}$ & & & & & $3.36(0.53)$ & .71 \\
\hline $\begin{array}{l}\text { CCS communication } \\
\text { related barriers }\end{array}$ & $\begin{array}{l}\text { "I do not know whom to talk and what to say } \\
\text { to arrange my CCS," "Asking about CCS is } \\
\text { difficult," "I can t find appropriate words to } \\
\text { discuss CCS and its results," "I feel unsure } \\
\text { when discussing CCS with a doctor," own } \\
\text { items based on results of an elicitation study }\end{array}$ & 4 & $1-4^{\mathrm{c}}$ & & & & & $3.40^{\mathrm{d}}(0.54)$ & .84 \\
\hline Social-related pros & $\begin{array}{l}\text { "It would be good for me and my life partner" } \\
\text { (social-related items from CCS pros measure; } \\
\text { Luszczynska et al., 2011) }\end{array}$ & 3 & $1-4^{\mathrm{c}}$ & & & & & $2.84(0.67)$ & .62 \\
\hline
\end{tabular}

Note. CCS = cervical cancer screening; ${ }^{a}$ mean item response; ${ }^{b}$ Kappa coefficient; ${ }^{c}$ response scale from "definitely not true" to "exactly true"; ${ }^{\text {reversed score. }}$ 
related beliefs (self-efficacy and control-related pros), which in turn were specified as the variables directly related to CCS intentions. Past behavior was assumed to relate to intention of future screening uptake. Following Kenny, Kashy, and Bolger's (1998) suggestions, the authors assumed two essential steps in establishing mediation: (1) the independent variable related to the mediator, and (2) the mediator was associated with the outcome variable. Sobel $Z$ test was used to test if the hypothesized mediation was significant. Additional analyses tested if education and age moderated the relationships between empowerment and the mediators using interaction terms (empowerment $\times$ age and empowerment $\times$ education) added to the models.

Potential confounders, such as education, financial status, and knowledge were included in the path model. The exogenous variables are usually assumed to be associated (Byrne, 2009), thus all confounders and past behavior were allowed to covary. Disturbances of the mediators were also assumed to covary. Across analyses respective coefficients were small in size and ranged from .05 to .26 .

Fit indices such as $\chi^{2} / \mathrm{df}$, Tucker-Lewis Index (TLI), Comparative Fit Index (CFI), and Root Mean Square Error of Approximation (RMSEA) were applied (Byrne, 2009). The values of TLI and CFI above 90 indicated adequate fit, whereas RMSEA values below .08 were considered as confirming reasonable model data-fit (cf. Byrne, 2009). The $\chi^{2} / \mathrm{df}$ ratio should vary between 0.9 and 3 or 5 (cf. Byrne, 2009). Statistical power analyses indicated that assuming small to medium effect sizes and accounting for the hypothesized number of parameters in the model, the sample should include a total of at least 355 participants to provide $80 \%$ power with a two-sided alpha of .05 . Missing data were handled by using a full information maximum likelihood method (Byrne, 2009), after testing for multivariate data normality. Mardia index (Byrne, 2009) below 5 usually indicates that the multivariate distribution does not differ significantly from normal.

Results

Participants were 386 women, aged 18-65 years $(M=35.15$ years, $S D=$ 14.04); $11 \%$ had primary education; $35.7 \%$ had completed high school; $9.4 \%$ were in college; $9.9 \%$ had a BA degree, and 34\% had a MA/PhD degree. A majority of respondents were either married (40.8\%) or living in a domestic relationship (36.5\%); $23.1 \%$ were single; $6.7 \%$ were divorced or separated; $2.9 \%$ were widows. Half of the sample $(53.6 \%)$ indicated that their economic situation was similar to the average situation of a family in their country, whereas $6.3 \%$ and $3.4 \%$ reported that their economic situation was respectively, slightly, or much below the average; $26.8 \%$ indicated that their economic situation was slightly above the average, and 9.9\% reported their economic situation as much above average. A total of $51 \%$ were full-time permanent employees, $4.9 \%$ were part-time permanent employees, and $6.7 \%$ 
short-term, part-time employees, $27.9 \%$ were students or retired; $9.1 \%$ were unemployed. One in three respondents lived in cities with more than 500,000 inhabitants (35.7\%), but $22 \%$ lived in rural or urban areas with less than 10,000 inhabitants.

Only $54 \%$ had attended any type of CCS within 3 years prior to the study. Past CCS was significantly related to intention to take up CCS ( $r=$ $.51, p<.001)$, control-related pros $(r=.19, p<.001)$ and self-efficacy $(r=$ $.12, p=.020)$. Intention was associated with control-related pros $(r=.34$, $p<.001)$ and self-efficacy $(r=.16, p=.001)$. Control-related pros and self-efficacy were moderately associated $(r=.20, p<.001)$. Empowerment was associated with control-related pros $(r=.12, p=.019)$ and self-efficacy $(r=.12, p<.020)$, but it was unrelated to CCS intention $(r=.09, p=.069)$ and past behavior $(r=.03, p=.620)$.

In the next step, the relationships between empowerment, the mediators, CCS, and control variables were analyzed with path analysis. The modeldata fit was acceptable, with $\chi^{2} / \mathrm{df}=2.31$, TLI $=.91$, CFI $=.90$, RMSEA $=$ .07 (90\% CI .06-.09), and data were distributed normally (Mardia index value of 4.06 , see Figure 1). The variables in the model explained $29 \%$ variance of CCS intention. As hypothesized, empowerment was related to CCS intention indirectly, with self-efficacy playing the mediating role (Sobel $Z=1.97, p=$ .049). Further, empowerment was related to control-related pros, which in turn were associated with intention to attend screening. Control-related pros constituted a significant mediator in the relationship between empowerment and CCS intention (Sobel $Z=2.06, p=.040$ ).

Finally, additional path analyses tested if interaction terms of empowerment $x$ age and empowerment $x$ education were related to the two

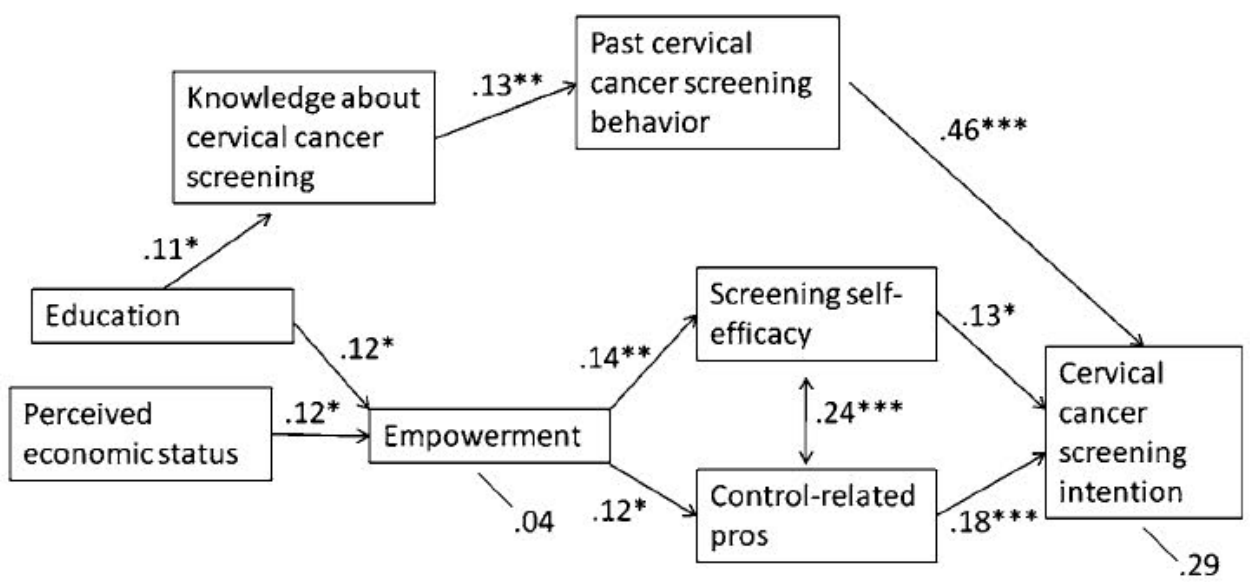

FIGURE 1 Results of path analysis (standardized solution), Study 1: Control-related mediators in the relationship between empowerment beliefs and intention to participate in cervical cancer screening. Figure note: ${ }^{*} p<.05,{ }^{* *} p<.01,{ }^{* * *} p<.001$. 
mediators. None of the associations between the interaction terms and the two mediators were statistically significant $(p>.16)$.

Study 1 concludes by indicating that women's empowerment and CCS intentions were not directly related. In contrast, empowerment may have prompted screening behavior by means of indirect mechanisms referring to control beliefs. In particular, women with high empowerment cognitions held stronger beliefs about their ability to uptake screening regardless of possible barriers and expected positive consequences of participation in CCS such as having control over their own health and body. These two types of control beliefs were directly related to CCS intentions.

\section{STUDY 2: EMPOWERMENT AND CCS \\ IN THE CONTEXT OF DISCOMFORT-RELATED \\ BARRIERS, WELL BEING-RELATED PROS, AND BODY SATISFACTION}

In Study 2 the authors aimed to analyze the second group of mediators, which referred to shame and discomfort-related barriers, well being-related pros (beliefs and expectations that CCS participation would result in positive outcomes, such as an increased sense of well being; cf. Luszczynska et al., 2011), positive evaluations of one's own body, and body satisfaction. As in Study 1, the authors hypothesized the relationship between women's empowerment and CCS intentions would be mediated by respective cognitions.

\section{Methods}

Data collection lasted one month (February 2011) with the same procedures and eligibility criteria as in Study 1. Those who agreed to take part signed a written informed consent. Free counselling sessions with a licensed psychologist were offered to all those who agreed to participate. Among the respondents, $4 \%$ were removed from analysis based on the exclusion criteria, and $2 \%$ refused to participate.

Measures of empowerment, cervical cancer intention, past CCS behavior, weight/appearance satisfaction, discomfort-related barriers, and knowledge were psychometrically evaluated in previous studies and showed satisfactory validity and reliability in original research, and adequate reliability of these questionnaires was also supported in the present study (Table 1). To assess well being-related pros, three items referring to well being applied in the earlier CCS study (Luszczynska et al., 2011) were used. To measure confounding variables items and analyses applied in Study 1 were used (Table 1).

To analyze data collected in Study 2, the same strategies as those used in Study 1 were used. Path analysis was applied to test if empowerment may 
be indirectly related to CCS intentions (with discomfort related barriers, well being and satisfaction-related pros, and body satisfaction as the mediators). The hypothesized model included nine observed variables, representing respective mean item scores. The variables were identical as in Study 1, except for the three mediators, specific for the study aims. Fit indices, missing data treatment, and mediation tests applied were identical to those used in Study 1.

\section{Results}

Participants were 424 women, aged $18-65$ years $(M=35.86$ years, $S D=$ 13.93); $9.5 \%$ had primary education, $42 \%$ had completed high school, $7.8 \%$ were studying, $7.8 \%$ had a $\mathrm{BA}$ degree, and $31.1 \%$ had a $\mathrm{MA} / \mathrm{PhD}$ degree. As in Study 1, a majority of respondents were either married (49.2\%) or living in a domestic relationship (18.4\%), 18.4\% were single, $7.9 \%$ were divorced or separated, $2.9 \%$ were widows. More than half of the sample (56.5\%) indicated that the economic situation of their family was similar to the average; a minority reported that their economic situation was slightly (4.5\%) or much (1.7\%) below the average; $27.3 \%$ indicated that their economic situation was slightly above the average, and $10 \%$ much above average. Half of women (50.7\%) were full-time permanent employees, $8.8 \%$ were parttime permanent employees; $3.6 \%$ had a short-term, part-time employment; $7.8 \%$ were pensioners or retired; $29.1 \%$ were unemployed. One in three participants lived in cities with more than 500,000 inhabitants (30.8\%); 30.3\% lived in towns with 10,000 to 100,000 inhabitants, and $22.8 \%$ lived in rural or urban areas with less than 10,000 inhabitants.

Preliminary analyses indicated that $61 \%$ had attended CCS within 3 years prior to the study. Past CCS behavior was significantly related to intention to uptake CCS $(r=.47, p<.001)$ well being-related pros $(r=.28, p<$ $.001)$, discomfort-related barriers $(r=-.25, p<.001)$, and appearance and body weight satisfaction $(r=.15, p=.002)$. Intention was associated with well being related pros $(r=.43, p<.001)$, discomfort-related barriers $(r=-.25, p<.001)$, and appearance and weight satisfaction $(r=.19$, $p<.001)$. Discomfort-related barriers were negatively related to well being pros $(r=-.19, p<.001)$ and appearance/weight satisfaction $(r=-.20$, $p<.001)$, whereas the two latter variables were unrelated $(r=.06, p=$ .215). Empowerment was associated with well being-related pros $(r=.12$, $p=.016)$, discomfort-related barriers $(r=-.20, p<.001)$, appearance and weight satisfaction $(r=.23, p<.001)$, intention to uptake screening $(r=$ $.23, p<.001)$, and past CCS behavior $(r=.17, p<.001)$.

To test the relationships between empowerment, the mediators, intention to take up CCS, and control variables, path analysis was applied. The model-data fit was acceptable, $\chi^{2} / \mathrm{df}=2.66$, TLI $=.91$, CFI $=.93$, RMSEA $=$ .07 (90\% CI .06-.09), and data were distributed normally (Mardia index value 
of 3.61). Thirty percent of the variance in intention was explained (Figure 2). As hypothesized, an indirect association between empowerment and CCS intention was found. Specifically, when the relationship between empowerment and CCS intention was evaluated, significant mediating effects were found for well being-related pros (Sobel $Z=2.50, p=.012$ ), discomfortrelated barriers (Sobel $Z=1.99, p=.046$ ), and appearance and weight satisfaction (Sobel $Z=2.57, p=.010$ ).

To test further the role of sociodemographic variables, interaction terms of empowerment $x$ age and empowerment $\times$ education were incorporated into the path model. The empowerment $\times$ education interaction was unrelated to three mediators. The empowerment $\times$ age interaction was significantly associated with well being-related pros (standardized path coefficient $=-.16, p<.001$ ). The simple slopes for age were computed at two levels of the moderator: younger age (one standard deviation below the mean) and older age (one standard deviation above the mean). Among women with younger age well being-related pros were similar regardless of empowerment $(\beta=-.03, p=.901)$. Among older women, those with higher empowerment perceived higher well being-related pros than those with lower empowerment $(\beta=.22, p<.001)$.

Study 2 concluded by showing that women with high empowerment cognitions reported stronger beliefs that CCS participation results in higher

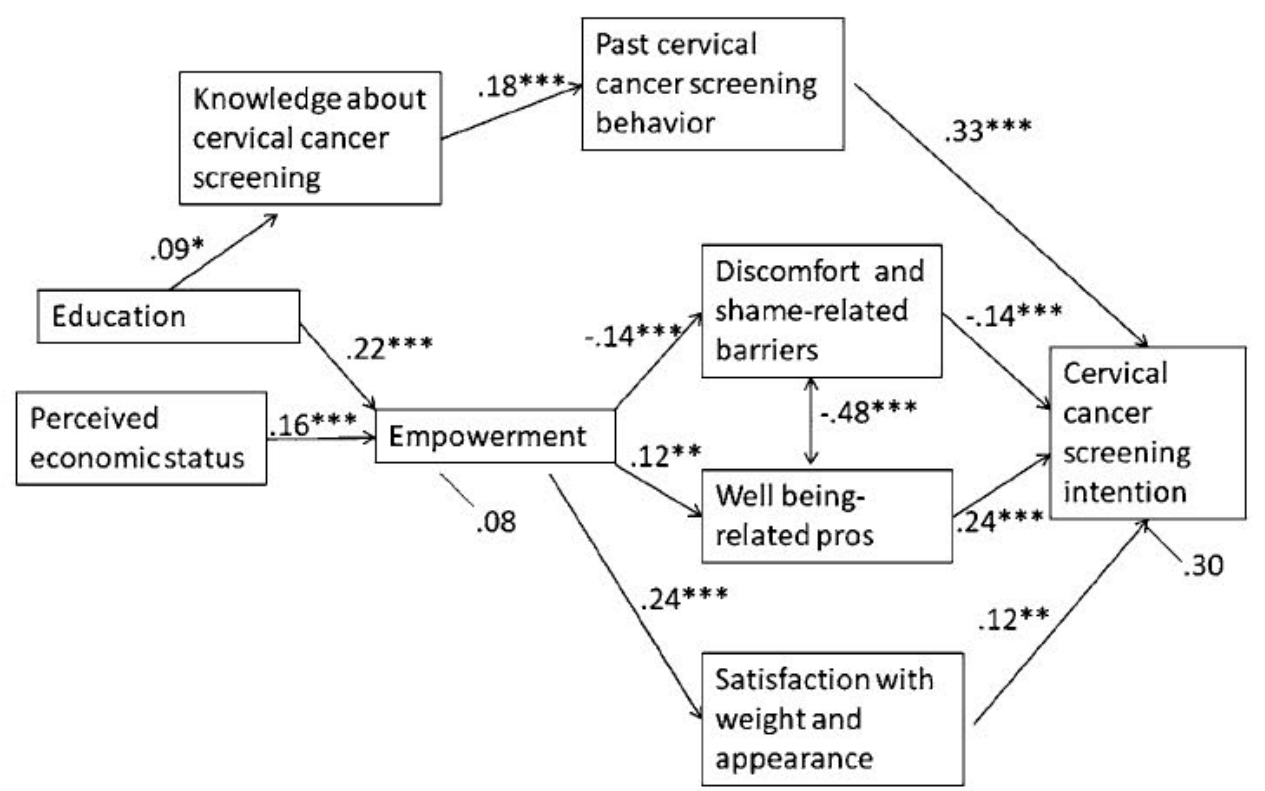

FIGURE 2 Results of path analysis (standardized solution), Study 2: Well being-related beliefs and expectations as the mediators in the relationship between empowerment beliefs and intention to participate in cervical cancer screening. Figure note: ${ }^{*} p<.05,{ }^{* *} p<.01,{ }^{* * *} p<$ .001 . 
well being, lower discomfort or shame, and they were more satisfied with their appearance and body weight. These beliefs, in turn, were directly related to intentions to participate in CCS.

\section{STUDY 3: RELATIONSHIP BETWEEN EMPOWERMENT AND CCS INTENTIONS MEDIATED BY SOCIAL SUPPORT, CCS COMMUNICATION-RELATED BARRIERS, AND SOCIAL FUNCTIONING-RELATED PROS}

In Study 3, the relationship between women's empowerment and CCS intentions was tested, mediated by perceived social support for screening, social-related pros (positive expectations of beneficial social consequences of participation in CCS, cf. Luszczynska, 2011), and lower CCS communicationrelated barriers (referring to discussing screening with medical personnel, friends, and family).

\section{Methods}

Data were collected online for two months (February-March 2011). The study was advertised at four non-commercial websites dealing with education, gender, and health issues, visited by women from in rural or urban areas across all regions of Poland. A brief introduction was followed by the link to the website. Potential respondents were informed about the purpose of the authors in the study and anonymity. Those who declared an interest were linked to the site including informed consent (similar procedures of obtaining informed consent were applied in previous research, e.g., Luszczynska et al., 2011). Participants were then offered a free counselling session (individual or telephone consultations) with a licensed psychologist, if they wished to discuss any issues addressed in the study. Finally, respondents were linked to the survey website.

Exclusion criteria were age below 18 or over 65 years, a history of hysterectomy or cervix amputation. Overall, $1.5 \%$ of respondents who did not meet eligibility criteria were excluded from analysis; $12 \%$ of women who discontinued filling out the questionnaire after its initial section were excluded.

Measures of empowerment, cervical cancer intention, past CCS behavior, and social support were psychometrically evaluated in previous studies that showed satisfactory validity and reliability, and adequate reliability of these measures was supported in the present study (Table 1). To assess pros referring to social functioning, three items on social benefits of CCS participation, applied in the earlier CCS study (Luszczynska et al., 2011) were used. The measure of communication related barriers was developed 
for the purpose of this study, based on an elicitation study (cf. Ajzen, 1991) conducted with 30 women. To measure controlled variables, items applied in previous research were used (Table 1).

Analytic procedures for Study 3 were similar to those used in Studies 1 and 2. Path analysis was applied to test if empowerment would be indirectly associated with CCS intentions (with social support, CCS communicationrelated barriers, and pros related to social consequences of CCS uptake as the mediators). The hypothesized model included nine observed variables, representing respective mean-item scores. Relationships among the variables under study were identical to Studies 1 and 2, except for the hypothesized mediators: Study 3 investigated three mediators (social support for CCS, CCS communication-related barriers, and pros referring to positive social consequences of CCS). Fit indices, missing data treatment, and mediation tests applied were identical to those used in Studies 1 and 2.

\section{Results}

Participants were 527 women, aged 18-65 years $(M=28.76$ years, $S D=$ 7.93); $1.9 \%$ had primary education; $19 \%$ had completed high school; $12.1 \%$ were in college; $9.8 \%$ had a BA degree, and $57.2 \%$ had a MA/PhD degree. A majority of respondents were either married (35.9\%) or living in a domestic relationship (39.4\%); 21.9\% were single, $2.1 \%$ were divorced or separated, $0.4 \%$ were widows. Almost half of the sample (43.5\%) indicated that their economic situation was similar to the average situation of a family in their country; $7 \%$ and $1.1 \%$ reported that their economic situation was respectively slightly or much below the average; $36.1 \%$ indicated that their economic situation was slightly above the average, and $12.2 \%$ much above average. In terms of employment $44.4 \%$ were full-time permanent employees; $8 \%$ were part-time permanent employees; $8.4 \%$ had a shortterm, part-time employment; $1.3 \%$ were pensioners or retired; $13.4 \%$ were unemployed. Half of the respondents lived in cities with more than 500,000 inhabitants (48.1\%), but $12.8 \%$ lived in rural or urban areas with less than 10,000 inhabitants.

Preliminary analyses indicated that only 69\% had attended CCS within 3 years prior to the study. Past CCS behavior was significantly related to intention $(r=.54, p<.001)$, social-related pros $(r=.16, p<.001)$, social support $(r=.27, p<.001)$, and CCS communication barriers, reversed score $(r=.35, p<.001)$. Intention was associated with social-related pros $(r=.25$, $p<.001)$, social support $(r=.37, p<.001)$, and CCS communication-related barriers $(r=.35, p<.001)$. Social-related pros were unrelated with social support $(r=.02, p=.684)$ or communication barriers $(r=.02, p=.707)$, whereas the two latter variables were moderately related $(r=.53, p<.001)$. Empowerment was associated with pros for social outcomes of CCS ( $r=$ $.13, p<.001)$, support for CCS $(r=.23, p<.001)$, and CCS communication 
skills ( $r=.24, p<.001)$, intention to uptake screening $(r=.11, p<.001)$, and past behavior $(r=.16, p<.001)$.

To test the relationships among empowerment, the social mediators, CCS, and control variables, path analysis was applied. The model-data fit was acceptable, $\chi^{2} / \mathrm{df}=2.83$, TLI $=.90$, CFI $=.92$, RMSEA $=.07$ (90\% CI $.06-$ .08 ), and data were distributed normally (Mardia index value of 4.21). The variables in the model explained 32\% variance of CCS intention (Figure 3). As hypothesized, empowerment was related to CCS intention indirectly. When the relationship between empowerment and intention was evaluated, significant mediating effects were found for social support for CCS (Sobel $Z=3.02, p=.003$ ), CCS communication skills (Sobel $Z=2.09, p=.036$ ), and social-related pros (Sobel $Z=2.31, p=.021$ ).

To test the potential role of sociodemographic variables, interaction terms of empowerment $\times$ age and empowerment $\times$ education were incorporated into the path model. The empowerment $\times$ age interaction term was unrelated to the mediators, but the empowerment $\times$ education interaction was significantly associated with social support for CSS (standardized path coefficient $=.11, p=.02$ ). The authors computed slopes for education at two levels of the moderator: education lower than a university degree and education equal to or higher than a BA degree. Among women with lower education, those with higher empowerment perceived more support

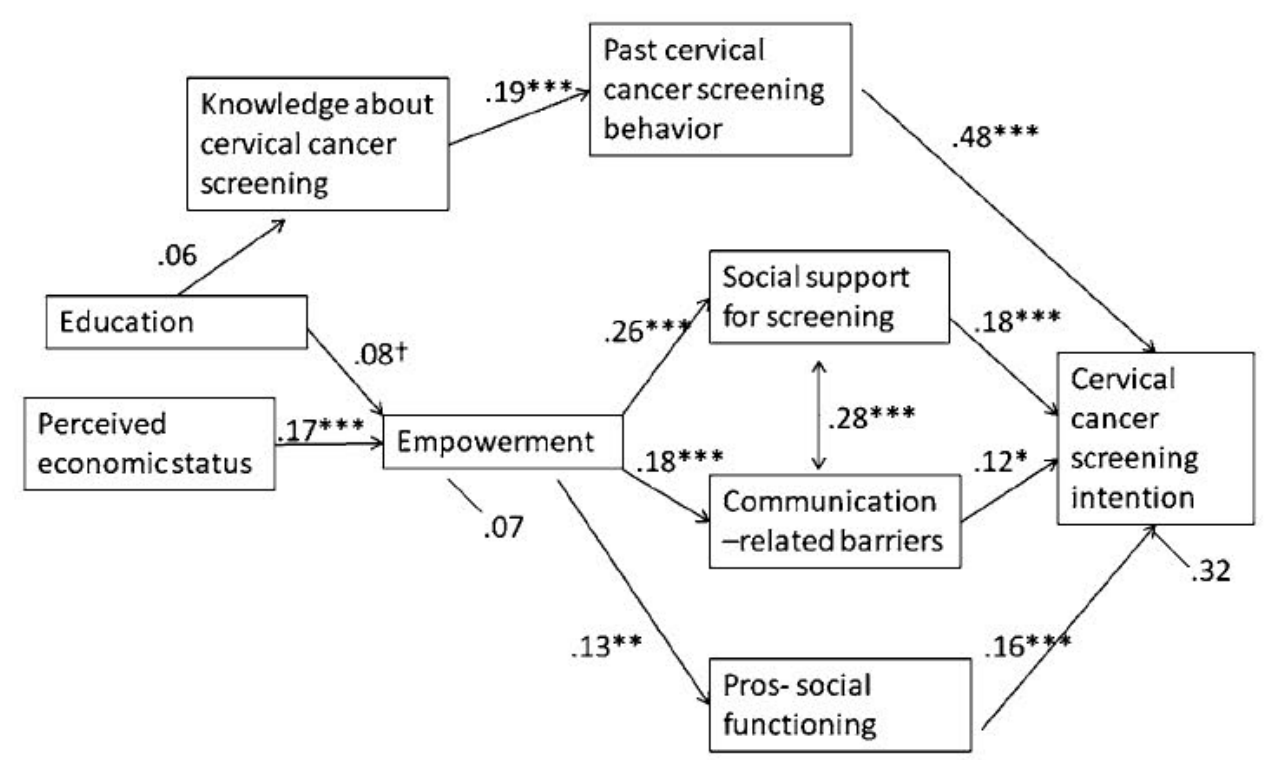

FIGURE 3 Results of path analysis (standardized solution), Study 3: Social functioning-related beliefs and expectations as the mediators in the relationship between empowerment beliefs and intention to participate in cervical cancer screening. Figure note: ${ }^{*} p<.05,{ }^{* *} p<.01$, ${ }^{* * *} p<.001$. 
than women with lower empowerment $(\beta=.17, p=.031)$. Among women with a university degree, social support reports were similar regardless of empowerment ( $\beta=.07, p=.853$ ).

The results of Study 3 conclude by suggesting that the associations between women's empowerment and CCS intentions were mediated by three variables relating to social functioning. As hypothesized, women with high empowerment beliefs perceived higher support for cancer screening, expected more positive social consequences of participation in CCS, and evaluated their communication skills as higher. The three mediator variables were, in turn, directly related to intentions to uptake CCS.

\section{GENERAL DISCUSSION}

The results of three studies elucidated the authors understanding of possible pathways through which empowerment beliefs may operate. These mediating mechanisms referred to perceptions and evaluations of control, social, and emotional functioning specific for CCS participation. Similar shares of variance of CSS intention were explained across the three studies, and therefore a cautious conclusion can be drawn that the hypothesized mediating mechanisms may have similar explanatory power.

These findings provided an empirical test for validity of the assumptions made by empowerment theories. As hypothesized by Johnson et al. (2005), the results indicated that empowerment enabled women to access and use external resources successfully (such as social support for CCS) and led to higher resilience in the face of obstacles (stronger self-efficacy beliefs). In line with Wittmann-Price's (2006) model, women's intentions to take up CCS were associated with perceptions of the internal barriers (discomfort, shame), environmental barriers (problems with communication about CCS), and opportunities (CCS as an opportunity to gain control over one's own health, become healthier, experience higher well being, and do something for a relationship with the loved-ones). Finally, as Beteta (2006) suggested, women who had strong empowerment beliefs were also found to evaluate their physical appearance more positively and were more satisfied with their body weight, which was in turn related with stronger intentions to partake in CCS.

Significant but weak associations between empowerment and controlrelated beliefs (such as self-efficacy or control-related pros) suggested that these two types of beliefs (and their measures) were clearly distinct in terms of their operationalization. Future research needs to analyze conceptual similarities and differences between empowerment and control beliefs. Although sociodemographic variables may be related to empowerment (Ahmed et al., 2010), the majority of analyzed mediations were not moderated by sociodemographic characteristics. 
Across the three studies only 54\%-69\% women attended CCS, which is consistent with research indicating low screening participation in Eastern European countries such as Poland (Spaczynski et al., 2010; Ulman-Wlodarz et al. 2011). Future research should investigate if enhancing empowerment could promote perceiving lower psychosocial barriers and higher psychosocial facilitators (e.g., social support, control beliefs), and thus increase CCS participation in countries where a remarkable proportion of women do not attend screening.

The results of these three studies also suggested that health behavior models may benefit from accounting for empowerment beliefs, in particular when explaining behaviors specific to women's health. Health behavior research has mostly accounted for the role of self- and internal regulation processes (Schwarzer, 2008), whereas the construct of empowerment emphasizes the role of environment and its regulation (cf. Johnson et al., 2006; Worell, 1996). Accounting for environmental factors in explaining behavior change may offer more opportunities to develop effective interventions.

\section{LIMITATIONS}

Although the strength of these studies was in using different data collection strategies (web-based and questionnaires filled out individually), these studies had several limitations. First, the research applied a narrow definition and operationalization of empowerment; therefore, any conclusions are limited to the aspects of empowerment evaluated in the three studies. Second, the cross-sectional designs limited the authors ability to assess temporal relations among variables. Experimental or longitudinal research would allow for stronger (or causal) conclusions. Third, convenience samples were used; therefore, the results have to be considered preliminary and should not be generalized to other populations of women. The majority of participants in all three studies had postgraduate education, which further limits the generalizability of the results. Although controlled in analyses, education remains related to empowerment (Ahmed et al., 2010) and may be considered as a moderator in future studies. Further, several of the mediator measures applied in the three studies consisted of items derived from previously developed measures, or in one case the measure was developed specifically for Study 3. Such strategy results in limited psychometric quality of these measures. Strategies of applying derived items rather than full measures are applied in other research (Schwarzer, 2008), but obtained results should be treated with caution. Although the socioeconomic characteristics of the sample were similar to the general population of Poland, a majority of the participants were below 40 years old; hence, any conclusions should not be generalized to older women. 


\section{GENERAL CONCLUSION}

Studies 1-3 provided support for the three hypothesized mediating mechanisms, explaining the associations between women's empowerment beliefs and intentions to engage in CCS. Those mediating mechanisms referred to social support receipt and such cognitions as self-efficacy, perceived barriers, expected positive consequences of screening in the areas of gaining control, social functioning, and emotional well being (e.g., discomfort, shame, satisfaction with appearance).

\section{REFERENCES}

Ahmed, S., A. A. Creanga, D. G. Gillespie, and A. O. Tsui. 2010. Economic status, education and empowerment: Implications for maternal health service utilization in developing countries. PLOS ONE 5:e11190.

Ajzen, I. 1991. The theory of planned behavior. Org Beh Hum Dec Proc 50:179-211.

Arbyn, M., A. O. Raifu, E. Weiderpass, F. Bray, and A. Anttila. 2009. Trends of cervical cancer mortality in the members of states of the European Union. Eur J Cancer 45:2640-8.

Bandura, A. 1997. Self-efficacy: The exercise of control. New York: Freeman.

Beteta, H. C. 2006. What is missing in measures of Women's Empowerment? J Hum Dev Capabilities 7:221-4.

Breitkopf, C. R., and H. C. Pearson. 2009. A theory-based approach to understanding follow-up of abnormal pap tests. J Health Psychol 14:361-71.

Byrne, B. M. 2009. Structural equation modeling with AMOS. Basic concepts, applications, and programming. New York: Routledge.

Chait, S. R., J. K. Thompson, and P. B. Jacobson. 2009. Relationship of body image to breast and skin self-examination intentions and behaviors. Body Image 6:603 .

Eaker, S., H. O. Adami, and P. Sparen. 2001. Attitudes to screening for cervical cancer: A population-based study in Sweden. Cancer Causes Control 12:51928.

Eggleston, K. S., A. L. Coker, I. P. Das, S. T. Cordray, and K. J. Luchok. 2007. Understanding barriers for adherence to follow-up care for abnormal pap tests. J Womens Health 16:311-30.

Johnson, D. M., J. Worell, and R. K. Chandler 2005. Assessing psychological health and empowerment in women: The personal progress scale revised. Women Health 41:109-29.

Kenny, D. A., D. A. Kashy, and N. Bolger. 1998. Data analysis in social psychology. In The handbook of social psychology, eds. Daniel T. Gilbert, Susan T. Fiske, and Gardner Lindzey, 233-65. Boston: McGraw-Hill.

Knops-Dullens, T., N. de Vries, and H. de Vries. 2007. Reasons for non-attendance in cervical cancer screening programmes: An application of the integrated model for behavioural change. Eur J Cancer Prev 16:436-45. 
Luszczynska, A., G. Goc, U. Scholz, M. Kowalska, and N. Knoll. 2011. Enhancing intentions to attend cervical cancer screening with a stage-matched intervention. BrJ Health Psychol 16:33-46.

Luszczynska, A., Y. Sarkar, and N. Knoll. 2007. Received social support, self-efficacy, and finding benefits in disease as predictors of physical functioning and adherence to antiretroviral therapy. Pat Edu Couns 66:37-42.

McAllister, M., K. Payne, R. Macleod, S. Nicholls, D. Donnai, and L. Davies. 2008. Patient empowerment in clinical genetics services. J Health Psychol 13:895-905.

Schwarzer, R. 2008. Modeling health behavior change: How to predict and modify the adoption and maintenance of health behaviors. Appl Psychol 57:1-29.

Spaczynski, M., A. Karowicz-Bilinska, W. Rokita, M. Molinks-Glura, L. JanuszekMichalecka, and P. Seroczynski. 2010. Attendance rate in the Polish cervical cancer screening program in years 2007-2009. Ginekol Pol 81:655-63.

Tanner-Smith, E. E., and T. N. Brown. 2010. Evaluating the health belief model: A critical review of studies predicting mammographic and pap screening. Soc Theory Health 8:95-125.

Tracy, J. K., A. D. Lydecker, and L. Ireland. 2010. Barriers to cervical cancer screening among lesbians. J Womens Health 19:229-37.

Ulman-Wlodarz, I., K. Nowosielski, M. Romanik, J. Pozowski, and M. Jurek. 2011. Awareness of cervical cancer prevention among patients of gynecological outpatient clinic. Ginekol Pol 82:22-5.

Wittmann-Price, R. A. 2006. Exploring the subconcepts of the Wittmann-Price theory of emancipated decision-making in women's health care. J Nurs Scholarsh 38:377-82.

Worell, J. 1996. Opening doors to feminist research. Psych Women Q 20:469-84. 